\title{
PRESCRIÇÃO E CRÉDITO TRIBUTÁRIO
}

\author{
Tax credit and prescription
}

\section{Tatiane Mattos França Bohmer}

Procuradora do Município de Pelotas (RS, Brasil). Especialista em Direito Processual pela Universidade Católica de Pelotas. Mestra em Ciências Sociais pela Universidade Católica de Pelotas.

\section{Lívia Pachalski Santin}

Graduanda do curso de Direito na Universidade Católica de Pelotas (RS, Brasil). Estagiária da Procuradoria do Município de Pelotas.

\begin{abstract}
Resumo
O presente artigo objetiva realizar uma análise da prescrição do crédito tributário após os entendimentos consagrados pelo Superior Tribunal de Justiça nos Temas 896 e 566. Cumpre destacar a relevância do assunto a ser abordado, considerando-se que a prescrição do crédito tributário fulmina com o próprio direito ao crédito. O tema será abordado a partir de análise aprofundada dos entendimentos jurisprudenciais do Superior Tribunal de Justiça, bem como através de decisões judiciais proferidas sobre o tema, com ênfase aos tributos municipais e às decisões enfrentadas pelo Município de Pelotas. Busca-se demonstrar as consequências da aplicação dos entendimentos consagrados pelo Superior Tribunal de Justiça no julgamento das demandas em que se discute a prescrição tributária, com sugestões para evitar a prescrição do crédito nas hipóteses de parcelamento de ofício e finalizando, através de contribuições, com o intuito de afastar a prescrição dos créditos tributários nas hipóteses alcançadas pela aplicação do Tema 566.
\end{abstract}

Palavras-chave: Fazenda Pública. Prescrição. Crédito tributário. Jurisprudência. Superior Tribunal de Justiça

\section{Abstract}

The present article aims at conducting an analysis of the prescription of tax credit after the understandings established by the Supreme Court of Justice on the Themes 896 and 566. It should be emphasized the relevance of the issue to be addressed, considering the prescription of tax credit ends the right to the credit itself. The theme is to be addressed on the basis of a thorough analysis of the case law understandings of the Supreme Court of Justice, as wella as through court decisions issued on the theme, with emphasis on municipal taxes and the decisions faced by the City of Pelotas. We aim to present the consequences of the application of understandings established by the Supreme Court of Justice in the judgement of the demands in which the tax prescription is discussed, with suggestions to avoid the prescritpion of credit in hypothesis of installment of payment and finishing through contributions with the purpose of suspending the prescription of tax credits in the hypotheses reached by the Theme 566 application.

Keywords: Public Treasury. Prescription. Tax credit. Jurisprudence. Supreme Court of Justice.

\section{Sumário}

1. Introdução; 2. STJ e o Tema 980; 3. SJT e o Tema 566; 4. Conclusão; 5. Notas; Referências. 


\title{
1. INTRODUÇÃO
}

Um dos temas mais relevantes diz respeito à prescrição do crédito tributário no curso das execuções fiscais. Para os operadores do Direito que diariamente se deparam com decisões judiciais, em especial às que extinguem execuções pelo decurso do prazo de cinco anos, nas hipóteses de cobrança de crédito tributário, o tema é ainda mais intrigante.

Não se pode olvidar que a prescrição é um instituto previsto em nosso Ordenamento Jurídico visando à pacificação das relações jurídicas, pois tem a finalidade de evitar que demandas se eternizem sem solução.

Como ensina Luciano Amaro (1998):

\begin{abstract}
A certeza e a segurança do direito não se compadecem com a permanência, no tempo, da possibilidade de litígios instauráveis pelo suposto titular de um direito que tardiamente venha a reclamá-lo. Dormientibus non sucurrit jus. O direito positivo não socorre a quem permanece inerte, durante largo espaço de tempo, sem exercitar seus direitos. (AMARO, 1998, p. 372).
\end{abstract}

Sabe-se que, constituído o crédito tributário, a Fazenda Pública tem o prazo de cinco anos para cobrança, nos termos do artigo 174 do Código Tributário Nacional (CTN). ${ }^{1}$ Silenciando, incide a prescrição, fulminado não apenas com o direito de ação da Fazenda Pública, mas com o próprio crédito tributário.

Sobre o tema, é interessante lembrarmos os ensinamentos de Hugo de Brito Machado (1998). Vejamos:

\begin{abstract}
Dizer que a ação para a cobrança do crédito tributário prescreve em cinco anos significa dizer que a Fazenda Pública tem o prazo de cinco anos para cobrar judicialmente, para propor a execução do crédito tributário. Tal prazo é contado da constituição definitiva do crédito, isto é, da data em que não mais admita a Fazenda Pública discutir a seu respeito, em procedimento administrativo. Se não efetua a cobrança no prazo de cinco anos, não poderá mais fazê-lo. (MACHADO, 1998, p.151).
\end{abstract}

A prescrição originária já trouxe maiores debates, especialmente a respeito do termo inicial da prescrição nos casos das demandas sobre o Imposto Predial e Territorial Urbano (IPTU), matéria que atualmente já foi enfrentada pelo Superior Tribunal de Justiça (STJ) no julgamento do Recurso Especial - REsp no 1.641.011 - PA e do Recurso Especial - REsp. $n^{\circ}$ 1.297.599/PA, originando o Tema 980.

A prescrição intercorrente, da mesma forma, apresenta entendimento pacificado atualmente pelo Colendo Superior Tribunal de Justiça, pois a matéria foi enfrentada no julgamento do Recurso Especial - REsp n¹.340.553/RS, originando o Tema 566.

A partir desses entendimentos é que se dará sequência ao trabalho para análise das repercussões do entendimento jurisprudencial do Superior Tribunal de Justiça a respeito da prescrição do crédito tributário no curso das execuções fiscais.

\section{STJ E O TEMA 980}

A Primeira Seção do Superior Tribunal de Justiça (STJ), ao apreciar o Recurso Especial - REsp. 1641.011 - PA, juntamente com o Recurso Especial - REsp. 1.297.599/PA, admitidos como representativos de controvérsia e cadastrados sob o Tema 980, apresentou inovações sobre o posicionamento do início da contagem da prescrição para a cobrança 
do Imposto Predial e Territorial Urbano (IPTU). Ademais, apresentou entendimento sobre a interrupção da prescrição pelos parcelamentos de ofício.

Cumpre destacar que o Superior Tribunal de Justiça entendeu que o termo inicial da prescrição do IPTU é o dia seguinte ao termo estipulado pela lei local para o vencimento da exação. Não bastasse, acabou por decidir que o parcelamento de ofício não pode servir como causa interruptiva da prescrição. A matéria ficou ementada da seguinte forma:

PROCESSUAL CIVIL E TRIBUTÁRIO. RECURSO ESPECIAL REPRESENTATIVO DA CONTROVÉRSIA. IPTU. PRESCRIÇÃO. TERMO INICIAL. DIA SEGUINTE AO VENCIMENTO DA EXAÇÃO. PARCELAMENTO DE OFÍCIO DA DÍVIDA TRIBUTÁRIA. NÃO CONFIGURAÇÃO DE CAUSA SUSPENSIVA DA CONTAGEM DA PRESCRIÇÃO. MORATÓRIA OU PARCELAMENTO APTO A SUSPENDER A EXIGIBILIDADE DO CRÉDITO TRIBUTÁRIO. NECESSÁRIA MANIFESTAÇÃO DE VONTADE DO CONTRIBUINTE. PARCELAMENTO DE OFÍCIO. MERO FAVOR FISCAL. APLICAÇÃO DO RITO DO ART. 1.036 E SEGUINTES DO CPC/2015. ART. 256-I DO RISTJ. RECURSO ESPECIAL DO MUNICÍPIO DE BELÉM/PAA QUE SE NEGA PROVIMENTO.

1. Tratando-se de lançamento de ofício, o prazo prescricional de cinco anos para que a Fazenda Pública realize a cobrança judicial de seu crédito tributário (art. 174, caput do CTN) referente ao IPTU, começa a fluir somente após o transcurso do prazo estabelecido pela lei local para o vencimento da exação (pagamento voluntário pelo contribuinte), não dispondo o Fisco, até o vencimento estipulado, de pretensão executória legítima para ajuizar execução fiscal objetivando a cobrança judicial, embora já constituído o crédito desde o momento no qual houve o envio do carnê para o endereço do contribuinte (Súmula 397/STJ). Hipótese similar ao julgamento por este STJ do REsp. 1.320.825/RJ (Rel. Min. GURGEL DE FARIA, DJe 17.8.2016), submetido ao rito dos recursos repetitivos (Tema 903), no qual restou fixada a tese de que a notificação do contribuinte para o recolhimento do IPVA perfectibiliza a constituição definitiva do crédito tributário, iniciando-se o prazo prescricional para a execução fiscal no dia seguinte à data estipulada para o vencimento da exação. 2 . O parcelamento de ofício da dívida tributária não configura causa interruptiva da contagem da prescrição, uma vez que o contribuinte não anuiu. 3 . O contribuinte não pode ser despido da autonomia de sua vontade, em decorrência de uma opção unilateral do Estado, que resolve lhe conceder a possibilidade de efetuar o pagamento em cotas parceladas. Se a Fazenda Pública Municipal entende que é mais conveniente oferecer opções parceladas para pagamento do IPTU, o faz dentro de sua política fiscal, por mera liberalidade, o que não induz a conclusão de que houve moratória ou parcelamento do crédito tributário, nos termos do art. 151, I e VI do CTN, apto a suspender o prazo prescricional para a cobrança de referido crédito. Necessária manifestação de vontade do contribuinte a fim de configurar moratória ou parcelamento apto a suspender a exigibilidade do crédito tributário. 4. Acórdão submetido ao regime do art. 1.036 e seguintes do CPC/2015 (art. 256-I do RISTJ, incluído pela Emenda Regimental 24 de 28.9.2016), cadastrados sob o Tema 980/STJ, fixando-se a seguinte tese: (i) o termo inicial do prazo prescricional da cobrança judicial do Imposto Predial e Territorial Urbano - IPTU inicia-se no dia seguinte à data estipulada para o vencimento da exação; (ii) o parcelamento de ofício da dívida tributária não configura causa interruptiva da contagem da prescrição, uma vez que o contribuinte não anuiu. (STJ, $1^{\text {a }}$ SEÇÃO, RESP 1.641.011 - PA, Ministro Relator Napoleão Nunes Maia Filho, Data do Julgamento: 14/11/18).

Como visto, o Superior Tribunal de Justiça, ao apreciar o REsp 1641.011/PA em conjunto com o REsp. 1.297.599/PA, submetidos ao rito dos recursos repetitivos, fixou a seguinte tese representativa do Tema 980 :

(i) O termo inicial do prazo prescricional da cobrança judicial do Imposto Predial e Territorial Urbano - IPTU inicia-se no dia seguinte à data estipulada para o vencimento da exação;

(ii) O parcelamento de ofício da dívida tributária não configura causa interruptiva 
da contagem da prescrição, uma vez que o contribuinte não anuiu.

É importante ressaltar que o Superior Tribunal de Justiça, através do Tema 980, além de pacificar o tema, trouxe reflexos importantes para as execuções fiscais de IPTU, tendo em vista que o reconhecimento da prescrição originária do tributo não considerava as datas previstas para o pagamento na legislação dos entes municipais, o que representava prejuízo ao ente público, especialmente em se tratando de IPTU que é um tributo anual.

Em atuação na Área Fiscal na Procuradoria do Município de Pelotas, não raras vezes, nos deparamos com o reconhecimento da prescrição de créditos tributários de Imposto sobre a Propriedade Territorial Rural (IPTU) e sobre o Imposto Sobre Serviços de Qualquer Natureza (ISSQN).

As prescrições de IPTU, quando reconhecidas na origem atreladas ao Município de Pelotas, usualmente aplicavam o entendimento de que a contagem do prazo prescricional se iniciava no primeiro dia do exercício seguinte aquele que o lançamento poderia ser efetuado.

Com o advento do Tema 890 do STJ e aplicação do novo entendimento pelo nosso Tribunal de Justiça, consoante decisão já proferida pela Segunda Câmara Cível do Tribunal de Justiça do RS, reconhecendo que a prescrição do IPTU deve considerar a Lei do Município local, abre-se uma nova possibilidade para a apreciação das demandas que envolvem a apreciação da prescrição originária do IPTU, trazendo novos fundamentos jurídicos para recursos que envolvem o tema, objetivando afastar o reconhecimento da prescrição, conforme o seguinte decisum:

\begin{abstract}
Ementa: AGRAVO DE INSTRUMENTO. DIREITO TRIBUTÁRIO. EXECUÇÃO FISCAL. IPTU. PRESCRIÇÃO DIRETA. INOCORRÊNCIA. TEMA 980 DO STJ. CDA. DESNECESSIDADE DE SUBSTITUIÇÃO. PROSSEGUIMENTO DA EXECUÇÃO. PRECEDENTES DESTA CORTE. 1. O STJ, quando do julgamento do Tema 980 fixou a seguinte tese: (i) o termo inicial do prazo prescricional da cobrança judicial do Imposto Predial e Territorial Urbano - IPTU inicia-se no dia seguinte à data estipulada para o vencimento da exação; (ii) o parcelamento de ofício da dívida tributária não configura causa interruptiva da contagem da prescrição, uma vez que o contribuinte não anuiu. 2. No caso dos autos, está sendo cobrado o IPTU devido nos exercícios de 2013 a 2016. Assim, tendo em vista o vencimento do IPTU de 2013, em janeiro do mesmo ano, conforme disposto no art. 25 da Lei Municipal $n^{\circ}$ 96, de 1983, o exequente dispunha até janeiro de 2018 para ingressar com a ação. 3. Considerando que o feito foi ajuizado em $11 / 12 / 2017$, bem como que o marco interruptivo da prescrição retroage à data do ajuizamento do feito, inexiste prescrição direta no caso concreto. 4. Por outro lado, ainda que houvesse créditos excluídos (e não há) não haveria necessidade de substituição da CDA em questão. AGRAVO DE INSTRUMENTO PROVIDO, EM DECISÃO MONOCRÁTICA. (Agravo de Instrumento, № 70084384965 , Vigésima Segunda Câmara Cível, Tribunal de Justiça do RS, Relator: Luiz Felipe Silveira Difini, Julgado em: 29-07-2020).
\end{abstract}

Tratando-se de demandas que envolvem créditos tributários e que representam recursos para os entes públicos, a atuação das Procuradorias dos Municípios para afastar a prescrição e seguir com o curso das ações executivas necessariamente se faz necessária, mormente se consideramos a indisponibilidade do patrimônio público.

Por outro viés, questão importante a ser abordada a respeito do Tema 980 diz respeito aos parcelamentos de ofício, aqueles que se configuram com a mera adesão de proposta de parcelamento enviada ao contribuinte inadimplente, através do pagamento da primeira parcela. 
O parcelamento, como cediço, interrompe o prazo prescricional por força do artigo $174^{2}$ do CTN e também suspende a exigibilidade do crédito tributário, nos termos do artigo do $151^{3}$ do mesmo diploma legal.

Assim, foi de grande surpresa o entendimento do Superior Tribunal de Justiça exposto no Tema 980 a respeito do parcelamento de ofício, pois, pelas regras do Código Tributário Nacional, poderia se entender que a adesão do contribuinte, através do pagamento das parcelas objeto do parcelamento, suspenderia a exigibilidade do crédito, além do prazo prescricional.

O entendimento do C. Tribunal de Justiça, todavia, veio na contramão dos parcelamentos realizados por muitos municípios que, de certa forma, deverão tomar medidas administrativas para obter o consentimento explícito do contribuinte nos parcelamentos, sob pena de o crédito tributário ser extinto pela prescrição nas hipóteses de inadimplemento.

A prescrição do crédito tributário, como cediço, não se resumo à prescrição originária, na medida em que o decurso do prazo, após o ajuizamento das ações de execução, pode resultar na aplicação da prescrição intercorrente, a qual também foi objeto de análise do Superior Tribunal de Justiça, conforme passaremos a expor.

\section{STJ E O TEMA 566}

O Superior Tribunal de Justiça (STJ) foi novamente provocado a se posicionar sobre a prescrição do crédito tributário, pacificando o tema da prescrição intercorrente após o julgamento do Recurso Especial - REsp. 1.340.553/RS, julgado pelo rito dos recursos repetitivos, dando origem ao Tema 566, conforme ementa abaixo transcrita:

RECURSO ESPECIAL REPETITIVO. ARTS. 1.036 E SEGUINTES DO CPC/2015 (ART. 543-C, DO CPC/1973). PROCESSUAL CIVIL. TRIBUTÁRIO. SISTEMÁTICA PARA A CONTAGEM DA PRESCRIÇÃO INTERCORRENTE (PRESCRIÇÃO APÓS A PROPOSITURA DA AÇÃO) PREVISTA NO ART. 40 E PARÁGRAFOS DA LEI DE EXECUÇÄO FISCAL (LEI N. 6.830/80).

1. O espírito do art. 40 , da Lei n. $6 \cdot 830 / 80$ é o de que nenhuma execução fiscal já ajuizada poderá permanecer eternamente nos escaninhos do Poder Judiciário ou da Procuradoria Fazendária encarregada da execução das respectivas dívidas fiscais.

2. Não havendo a citação de qualquer devedor por qualquer meio válido e/ou não sendo encontrados bens sobre os quais possa recair a penhora (o que permitiria o fim da inércia processual), inicia-se automaticamente o procedimento previsto no art. 40 da Lei n. 6.830/80, e respectivo prazo, ao fim do qual restará prescrito o crédito fiscal. Esse o teor da Súmula n. 314/STJ: "Em execução fiscal, não localizados bens penhoráveis, suspende-se o processo por um ano, findo o qual se inicia o prazo da prescrição qüinqüenal intercorrente".

3. Nem o Juiz e nem a Procuradoria da Fazenda Pública são os senhores do termo inicial do prazo de 1 (um) ano de suspensão previsto no caput, do art. 40, da LEF, somente a lei o é (ordena o art. 40: "[...] o juiz suspenderá [...]"). Não cabe ao Juiz ou à Procuradoria a escolha do melhor momento para o seu início. No primeiro momento em que constatada a não localização do devedor e/ou ausência de bens pelo oficial de justiça e intimada a Fazenda Pública, inicia-se automaticamente o prazo de suspensão, na forma do art. 40, caput, da LEF. Indiferente aqui, portanto, o fato de existir petição da Fazenda Pública requerendo a suspensão do feito por $30,60,90$ ou 120 dias a fim de realizar diligências, sem pedir a suspensão do feito pelo art. 40, da LEF. Esses pedidos não encontram amparo fora do art. 40 da LEF que limita a suspensão a 1 (um) ano. Também indiferente o fato de que o Juiz, ao intimar a Fazenda Pública, não tenha expressamente feito menção à suspensão do art. 40 , da LEF. 0 que importa para a 
aplicação da lei é que a Fazenda Pública tenha tomado ciência da inexistência de bens penhoráveis no endereço fornecido e/ou da não localização do devedor. Isso é o suficiente para inaugurar o prazo, ex lege.

4. Teses julgadas para efeito dos arts. 1.036 e seguintes do CPC/2015 (art. 543-C, do CPC/1973):

4.1.) O prazo de 1 (um) ano de suspensão do processo e do respectivo prazo prescricional previsto no art. $40, \S \S 1^{\circ}$ e $2^{\circ}$ da Lei n. 6.830/80 - LEF tem início automaticamente na data da ciência da Fazenda Pública a respeito da não localização do devedor ou da inexistência de bens penhoráveis no endereço fornecido, havendo, sem prejuízo dessa contagem automática, o dever de o magistrado declarar ter ocorrido a suspensão da execução;

4.1.1.) Sem prejuízo do disposto no item 4.1., nos casos de execução fiscal para cobrança de dívida ativa de natureza tributária (cujo despacho ordenador da citação tenha sido proferido antes da vigência da Lei Complementar $n$. 118/2005), depois da citação válida, ainda que editalícia, logo após a primeira tentativa infrutífera de localização de bens penhoráveis, o Juiz declarará suspensa a execução.

4.1.2.) Sem prejuízo do disposto no item 4.1., em se tratando de execução fiscal para cobrança de dívida ativa de natureza tributária (cujo despacho ordenador da citação tenha sido proferido na vigência da Lei Complementar n. 118/2005) e de qualquer dívida ativa de natureza não tributária, logo após a primeira tentativa frustrada de citação do devedor ou de localização de bens penhoráveis, o Juiz declarará suspensa a execução.

4.2.) Havendo ou não petição da Fazenda Pública e havendo ou não pronunciamento judicial nesse sentido, findo o prazo de 1 (um) ano de suspensão inicia-se automaticamente o prazo prescricional aplicável (de acordo com a natureza do crédito exequendo) durante o qual o processo deveria estar arquivado sem baixa na distribuição, na forma do art. $40, \S \S 2^{\circ}, 3^{\circ}$ e $4^{\circ}$ da Lei n. $6.830 / 80-L E F$, findo o qual o Juiz, depois de ouvida a Fazenda Pública, poderá, de ofício, reconhecer a prescrição intercorrente e decretá-la de imediato:

4.3.) A efetiva constrição patrimonial e a efetiva citação(ainda que por edital) são aptas a interromper o curso da prescrição intercorrente, não bastando para tal o mero peticionamento em juízo, requerendo, v.g., a feitura da penhora sobre ativos financeiros ou sobre outros bens. Os requerimentos feitos pelo exequente, dentro da soma do prazo máximo de 1 (um) ano de suspensão mais o prazo de prescrição aplicável (de acordo com a natureza do crédito exequendo) deverão ser processados, ainda que para além da soma desses dois prazos, pois, citados (ainda que por edital) os devedores e penhorados os bens, a qualquer tempo - mesmo depois de escoados os referidos prazos -, considera-se interrompida a prescrição intercorrente, retroativamente, na data do protocolo da petição que requereu a providência frutífera.

4.4.) A Fazenda Pública, em sua primeira oportunidade de falar nos autos (art. 245 do CPC/73, correspondente ao art. 278 do CPC/2015), ao alegar nulidade pela falta de qualquer intimação dentro do procedimento do art. 40 da LEF, deverá demonstrar o prejuízo que sofreu (exceto a falta da intimação que constitui o termo inicial - 4.1., onde o prejuízo é presumido), por exemplo, deverá demonstrar a ocorrência de qualquer causa interruptiva ou suspensiva da prescrição.

4.5.) O magistrado, ao reconhecer a prescrição intercorrente, deverá fundamentar $o$ ato judicial por meio da delimitação dos marcos legais que foram aplicados na contagem do respectivo prazo, inclusive quanto ao período em que a execução ficou suspensa. Recurso especial não provido. Acórdão submetido ao regime dos arts. 1.036 e seguintes do CPC/2015 (art. 543-C, do CPC/1973). (STJ- REsp: 1340553 RS 2012/0169193-3, Relator: Ministro MAURO CAMPBELL MARQUES, Data do Julgamento: 12/09/2018, S1 - PRIMEIRA SEÇÃO, Data de Publicação: DJe 16/10/2018).

Embora o entendimento do C. STJ seja claro a respeito da prescrição intercorrente, não se pode deixar de ressaltar que tem causado prejuízos à Fazenda Pública, desconsiderando a indisponibilidade do patrimônio público, bem como o fato de que o crédito tributário é indispensável para a receita dos entes da federação. 
Ademais, há que se considerar que o entendimento atualmente consagrado a respeito da prescrição intercorrente trouxe alteração no entendimento até então aplicado pelo Tribunal de Justiça Gaúcho no sentido de que a prescrição intercorrente só era aplicado nas hipóteses de inércia da Fazenda Pública pelo prazo de cinco ou mais anos em se tratando de crédito tributário.

Sobre o tema, lembramos as lições de Luiz Felipe Silveira Difini (2006) em edição anterior ao entendimento consagrado no Tema 566 do STJ:

A prescrição intercorrente é aquela que flui no curso da ação: só se consuma se o processo fica paralisado, sem a prática de qualquer ato, pelo prazo prescricional, não por eventual demora na sua tramitação, enquanto o autor pratica atos processuais para seu impulsionamento. (DIFINI, 2006, p. 308).

As decisões eram pacíficas no sentido de que somente a inércia do ente público poderia levar ao reconhecimento da prescrição intercorrente, consoante se verifica através da seguinte ementa do julgamento ocorrido em 19 de dezembro de 2018 pela $1^{\text {a }}$ Câmara Cível do Tribunal de Justiça do Estado do RS.

Ementa: APELAÇÃO CÍVEL. EXECUÇÃO FISCAL. IPTU. PRESCRIÇÃO. POSSIBILIDADE DE JULGAMENTO MONOCRÁTICO. 1. PRESCRIÇÃO. 1.1 - Prescrição prévia ao ajuizamento. Exclui-se os exercícios de IPTU com prescrição já consumada quando ajuizado o processo. 1.2 - Prescrição intercorrente. 1.2.1 - Não há falar em prescrição intercorrente se não houve paralisação por desinteresse do credor durante mais de cinco anos. Além disso, impõe-se, previamente, o cumprimento dos $\S \S 2^{\circ}$ e $4^{\circ}$ do art. 40 da LEF e da Súm. 314 do STJ. 1.2.2 - A prescrição intercorrente existe para punir o credor negligente e para prestigiar o princípio da segurança jurídica, que não se coaduna com a eternização das pendências administrativas ou judiciais (STJ, REsp 1034191RJ, DJe de 26-5-08). Por isso, pressupõe-se negligência do credor. Não há confundi-la com cinco anos de tramitação do processo ou prazo ao pagamento, nem atividade processual, cuja ausência pode gerá-la. 2. POSSIBILIDADE DE JULGAMENTO MONOCRÁTICO 2.1 - A possibilidade de julgamento monocrático não se exaure nas hipóteses das alíneas dos incisos IV e $V$ do art. 932 do CPC/2015. Assim como em relação ao art. 557 do CPC/1973, há reconhecer duas hipóteses implícitas: (a) a lei; e (b) o princípio da jurisdição equivalente. 2.1.1 - Quanto à lei, se o relator pode desprover ou prover quando a decisão está conforme as categorias jurisprudenciais ou delas diverge, que vêm a ser as alíneas de tais incisos, com muito mais razão pode igualmente desprover ou prover quando a decisão está conforme a lei ou dela diverge, justificando, inclusive, noutras circunstâncias, ação rescisória. 2.1.2-Quanto ao princípio da jurisdição equivalente, consagrado pelo STJ à luz do ex-art. 557, impõe-se preservá-lo, agora, à luz do art. Se há orientação sedimentada no órgão colegiado, nada obsta o relator o recurso provê-lo ou desprovê-lo desde logo. Em tais situações, o relator nada mais faz do que entregar à parte a prestação jurisdicional que 932, IV e V, do novo CPC. e seria dada se julgado pelo órgão fracionário. Isso significa celeridade processual, fortemente estimulada pelo novo Estatuto no cumprimento do princípio da duração razoável do processo $\left(C F\right.$, art. $5^{\circ}, \mathrm{LXX}$ VIII; CPC/2015, art. $4^{\circ}$ ). 2.2 - Subsiste após a entrada em vigor do CPC/2015, o entendimento de que, se o órgão colegiado confirma a decisão do relator, fica automaticamente prejudicada eventual arguição de não ser caso de decisão monocrática. 2.3 - As contrarrazões previstas no art. 932, V, e a intimação pessoal do agravado prevista no art. 1.019, II, quando não tiver procurador constituído, não podem ser entendidas de modo amplo, a ponto de obrigar o $2^{\circ} \mathrm{Grau}$ citar e intimar quando isso ainda não ocorreu no $1^{\circ}$. Menos ainda quando se discute em juízo provisório, se a parte deve ou não figurar no polo passivo, ou se deve ou não ser citada por edital, até porque, se for o caso, poderá se defender, no momento oportuno. A interpretação literal de tais dispositivos sobrecarrega o $2^{\circ} \mathrm{Grau}$ em atos inúteis, o que não está conforme a razoabilidade e a eficiência (art. $8^{\circ}$ ). 2. DISPOSITIVO Apelação provida em parte. (Apelação Cível, $N^{\circ}$ 70080066525, Primeira Câmara Cível, Tribunal de Justiça do RS, Relator: Irineu Mariani, Julgado em: 19-12-2018) 
O Tema 566, contudo, inovou, surpreendendo em especial os procuradores públicos, na medida em que desconsiderou prescrições legais, como a regra prevista no artigo 25 da Lei de Execução Fiscal ${ }^{4}$ que determina a intimação pessoal da Fazenda Pública, ao reconhecer a suspensão automática do processo nas hipóteses em que não encontrado o devedor ou bens para garantir a execução.

Nesse contexto, o Tema 566, em que pese tenha sido proferido com o intuito de pacificar as relações jurídicas, suprimindo do mundo jurídico demandas que se perpetuassem por um longo prazo sem êxito, desestabilizou o entendimento já pacificado sobre a matéria, trazendo surpresa aos operadores do Direito Tributário e prejuízos à Fazenda Pública, especialmente porque a aplicação do entendimento consagrado pelo Superior Tribunal de Justiça sequer observou uma regra de transição, ocasionando a aplicação do entendimento inclusive para demandas que já estavam tramitando antes da edição do Tema, gerando surpresa ao procurador público que, sem sequer ser intimado do início da suspensão do feito pelo artigo 40 da Lei de Execução Fiscal, ${ }^{5}$ vê o reconhecimento da prescrição de créditos tributários pelo mero decurso do prazo de cinco ou mais anos, após o decurso de 1 (um) ano sem que a Fazenda Pública tenha obtido êxito em citar o executado ou em encontrar bens para garantir e prosseguir com a execução.

Portanto, acredita-se que deveria ter havido a modulação dos efeitos do julgamento proferido pelo Superior Tribunal de Justiça ao julgar o tema da prescrição intercorrente para que houvesse estabilização das relações jurídicas nas demandas em que figuram a Fazenda Pública, preservando-se os créditos tributários em prol da indisponibilidade do interesse público.

Em estudo recente realizado sobre a prescrição com base na aplicação do Tema 566 em processos da Procuradoria do Município de Pelotas, verificou-se que a aplicação do novo entendimento do C. Superior Tribunal de Justiça, sem a modulação dos efeitos, ocasionou prejuízo ao ente público em menos de 01 ano (de julho de 2019 a março de 2020) no valor de $\mathrm{R} \$ 709.225,30$ (setecentos e nove mil duzentos e vinte e cinco reais e trinta centavos). ${ }^{6}$

A pesquisa demonstrou, ainda, que em alguns processos extintos, o Tema 566 não foi observado na íntegra, na medida a sentença extintiva desconsiderou que alguns processos, em razão de eventual parcelamento realizado pela parte, tinham sido arquivados com baixa pelo cartório. A sentença extintiva desconsiderou também o fato de que a Fazenda Pública não havia sido intimada para apresentar manifestação ao final do tempo em que o processo deveria estar arquivado sem baixa pelo cartório. Nesses processos, o Município buscou a reforma do julgado, conseguindo êxito em algumas demandas, conforme a que segue:

Ementa: Apelação Cível. DIREITO TRIBUTÁRIO. EXECUÇÃO FISCAL. PRESCRIÇÃO INTERCORRENTE NÃO CARACTERIZADA. APLICAÇÃO DO ART. 40 DA LEF E DA SÚMULA 314 DO STJ observância da ORIENTAÇÃO DO STJ NO JULGAMENTO DO RESP N $1.340 .553 / R S$. TEMAS 566, 567, 568, 569 , 570 E 571. 1. Segundo o posicionamento do STJ a respeito da contagem do prazo para a prescrição intercorrente, resultando infrutíferas as tentativas de localização do devedor e de bens passiveis de expropriação, o juiz declarará suspensa a execução pelo prazo de um ano e, findo o prazo, iniciar-se-á automaticamente a contagem do prazo prescricional aplicável, independente do processo estar arquivado administrativamente, e somente depois de transcorrido o lapso temporal e de ouvida previamente a Fazenda Pública, o juiz poderá 


\begin{abstract}
reconhecer a prescrição intercorrente. 2. De acordo com os atos processuais praticados na presente execução fiscal, embora seja possível considerar a suspensão automática do processo, a Fazenda Pública não foi previamente intimada para apresentar manifestação ao final do tempo que o processo deveria estar arquivado sem baixa na distribuição, requisito indispensável para o reconhecimento da prescrição intercorrente. 3. Não há falar em prescrição intercorrente, porquanto não observados os ditames do art. $40, \S 4^{\circ}$, da Lei $n^{\circ} 6.830 / 80$. RECURSO PROVIDO, EM DECISÃO MONOCRÁTICA. (TJRS, AP70081834947, $1^{\text {a }}$ Câmara Cível, Recorrente: Município de Pelotas, Recorrido: CASARIN COMERCIO DE ALIMENTOS LTDA; Decisão de13/06/2019).
\end{abstract}

Como se pode observar, o tema prescrição do crédito tributário ainda merece reflexões, especialmente se considerarmos que o novo entendimento do Superior Tribunal de Justiça, em especial do Tema 566, acabou por alterar entendimentos já pacificados sobre o tema e que garantiam à persecução das execuções fiscais para a cobrança do crédito tributário desde que não fosse constatada a inércia da Fazenda Pública.

\title{
4. CONCLUSÃO
}

A prescrição do crédito tributário é um dos temas que mais se discute no curso das execuções fiscais. Nos processos que tramitam na Comarca de Pelotas e que são decorrentes da Procuradoria do Município é um tema que vem sendo questionado, considerando-se o elevado número de processos extintos pelo reconhecimento da prescrição intercorrente, quer em decorrência do decurso do prazo superior a cinco anos sem a localização dos executados para concretizar a citação, quer em decorrência do decurso do prazo superior a cinco anos sem a localização de bens para garantir a execução e prosseguir com o processo executivo, quer, ainda, em decorrência de processos que ficaram por prazo superior a cinco anos arquivados com baixa nos cartórios em decorrência da realização de parcelamentos pelos executados.

Como já referido, o entendimento jurisprudencial dominante do Tribunal de Justiça do Rio Grande do Sul sobre a temática, anterior ao Tema 566, era o de que a prescrição intercorrente não era aplicada se não restasse configurada a inércia da Fazenda Pública, ou seja, a não impulsão do processo por cinco ou mais anos nas hipóteses de crédito tributário.

O Tema 566, entretanto, trouxe entendimento distinto do até então aplicado, surpreendendo a Fazenda Pública que, a partir de então, passou a visualizar o reconhecimento da prescrição do crédito tributário em processos que, não obstante impulsionados pela Fazenda Pública, não seguiram seu curso normal por não se ter obtido êxito em localizar o devedor que, como cediço, muitas vezes se oculta, ou porque não se conseguiu obter bens para indicar à penhora e prosseguir com a execução fiscal.

Ocorre que a não localização do devedor ou a não localização de bens para prosseguir a execução não decorre de falta da Administração Pública que sempre diligencia para obtenção de informações para prosseguir com a execução, obtendo a satisfação do crédito tributário.

Nesse contexto, entende-se que o atual posicionamento do Superior Tribunal de Justiça a respeito do reconhecimento da prescrição intercorrente pelo decurso do prazo de cinco anos contados a partir do término de um ano da suspensão automática do processo - que se configura no momento da ciência da Fazenda Pública a respeito da não localização do 
devedor ou da inexistência de bens penhoráveis - privilegia o devedor inadimplemento que, muitas vezes, se oculta ou ao patrimônio.

Assim, concluiu-se que o Tema 566 trouxe prejuízos aos entes públicos, na medida em que impõe uma alteração nos entendimentos já consolidados sobre a prescrição intercorrente perante os Tribunais de Justiça, especialmente porque não houve uma modulação dos efeitos do julgamento proferido pelo rito dos casos repetitivos.

Verifica-se, igualmente, prejuízo à Fazenda Pública na Edição do Tema 890, mais especificamente na parte em que desconsidera o parcelamento de ofício como causa suspensiva ou interruptiva da prescrição, em que pese o artigo 151 do CTN $^{7}$ seja claro em prever o parcelamento como forma de suspensão da exigibilidade do crédito tributário e a regra prevista no artigo $174, \mathrm{IV}^{8}{ }^{8}$ do mesmo diploma legal, tenha previsto que se considera interrompida a prescrição por qualquer ato inequívoco que importe em reconhecimento do débito pelo devedor.

Acredita-se que a decisão proferida pelo Superior Tribunal de Justiça que deu origem ao Tema 890 certamente fará com que a Administração Pública possibilite, de alguma forma, a adesão expressa do contribuinte ao parcelamento de ofício, sob pena de ser futuramente surpreendida com o decurso do prazo prescricional em eventual futura cobrança do crédito tributário nas hipóteses de inadimplemento.

Ademais, acredita-se que, naquelas hipóteses em que o Tema 566 venha a ser aplicado de forma equivocada ao caso concreto, extinguindo-se execuções em decorrência do reconhecimento da prescrição em processos que estiveram arquivados com baixa ou sem a anterior intimação da Fazenda Pública para que se manifestasse, por exemplo, possa-se utilizar o instituto da reclamação, previsto no artigo $988^{\circ}$ do Código de Processo Civil, como mais uma alternativa para questionar o tema e uma forma de tentar afastar a prescrição equivocadamente reconhecida, preservando-se a autoridade do Tribunal.

Por derradeiro, não se pode deixar de ressaltar, em prol do princípio da segurança jurídica e da irretroatividade da mutação jurisprudencial, que o Colendo Superior Tribunal de Justiça pecou ao não limitar os efeitos no julgamento dos recursos repetitivos que deram origem aos Temas 980 e 566, considerando-se a regra prevista no artigo 927, $\S 3^{\circ}$, do Código de Processo Civil, ${ }^{10}$ bem como os prejuízos que estão sendo suportados pela Fazenda Pública, mais especificamente em decorrência da aplicação cega e sem limitação do Tema 566.

É oportuno ressaltar que a mudança de entendimento jurisprudencial da Corte autoriza a modulação dos efeitos em casos de recursos repetitivos. Nesse sentido, inclusive, o entendimento da $1^{\text {a }}$ Turma do Superior Tribunal de Justiça no julgamento do REsp 1.596.978, conforme menciona Bárbara Mengargo (2016).

\section{NOTAS}

1. "Art. 174. A ação para a cobrança do crédito tributário prescreve em cinco anos, contados da data da sua constituição definitiva".

(BRASIL. Lei n. 5.172/66, de 25 de outubro de 1966. Dispõe sobre o Sistema Tributário Nacional e institui normas gerais de direito tributário aplicáveis à União, Estados e Municípios. Brasília, DF: Presidência 
da República, 1966. Disponível em: http://www.planalto.gov.br/ccivil_03/leis/15172compilado.htm_. Acesso em: 6 nov. 2020).

2. BRASIL. Lei n. 5.172/66, de 25 de outubro de 1966. Dispõe sobre o Sistema Tributário Nacional e institui normas gerais de direito tributário aplicáveis à União, Estados e Municípios. Brasília, DF: Presidência da República, 1966.

3. "Art. 151. Suspendem a exigibilidade do crédito tributário:

I- moratória;

II - o depósito do seu montante integral;

III - as reclamações e os recursos, nos termos das leis reguladoras do processo tributário administrativo;

IV - a concessão de medida liminar em mandado de segurança.

V - a concessão de medida liminar ou de tutela antecipada, em outras espécies de ação judicial;

VI - o parcelamento.

Parágrafo único. O disposto neste artigo não dispensa o cumprimento das obrigações assessórias dependentes da obrigação principal cujo crédito seja suspenso, ou dela consequentes." data da sua constituição definitiva".

(BRASIL. Lei n. 5.172/66, de 25 de outubro de 1966. Dispõe sobre o Sistema Tributário Nacional e institui normas gerais de direito tributário aplicáveis à União, Estados e Municípios. Brasília, DF: Presidência da República, 1966. Disponível em: http://www.planalto.gov.br/ccivil_03/leis/15172compilado.htm_. Acesso em: 6 nov. 2020).

4. "Art. 25 - Na execução fiscal, qualquer intimação ao representante judicial da Fazenda Pública será feita pessoalmente.

Parágrafo Único - A intimação de que trata este artigo poderá ser feita mediante vista dos autos, com imediata remessa ao representante judicial da Fazenda Pública, pelo cartório ou secretaria". (BRASIL. Lei n. 6.830/80, de 22 de setembro de 1980. Dispõe sobre a cobrança judicial da Dívida Ativa da Fazenda Pública, e dá outras providências. Brasília, DF: Presidência da República, 1980. Disponível em: http:// www.planalto.gov.br/ccivil_03/leis/l6830.htm._Acesso em: nov. 2020).

5. "Art. 40 - O Juiz suspenderá o curso da execução, enquanto não for localizado o devedor ou encontrados bens sobre os quais possa recair a penhora, e, nesses casos, não correrá o prazo de prescrição.

$\S 1^{\circ}$ - Suspenso o curso da execução, será aberta vista dos autos ao representante judicial da Fazenda Pública.

$\S 2^{\circ}$ - Decorrido o prazo máximo de 1 (um) ano, sem que seja localizado o devedor ou encontrados bens penhoráveis, o Juiz ordenará o arquivamento dos autos.

$\S 3^{\circ}$ - Encontrados que sejam, a qualquer tempo, o devedor ou os bens, serão desarquivados os autos para prosseguimento da execução.

$\S 4^{\circ}$ - Se da decisão que ordenar o arquivamento tiver decorrido o prazo prescricional, o juiz, depois de ouvida a Fazenda Pública, poderá, de ofício, reconhecer a prescrição intercorrente e decretá-la de imediato.

$\S 5^{\circ}$ - A manifestação prévia da Fazenda Pública prevista no $\S 40$ deste artigo será dispensada no caso de cobranças judiciais cujo valor seja inferior ao mínimo fixado por ato do Ministro de Estado da Fazenda". (BRASIL. Lei n. 6.830/80, de 22 de setembro de 1980. Dispõe sobre a cobrança judicial da Dívida Ativa da Fazenda Pública, e dá outras providências. Brasília, DF: Presidência da República, 1980. Disponível em: http://www.planalto.gov.br/ccivil_03/leis//6830.htm. Acesso em: nov. 2020).

6. PACHALSKI, L. Arrecadação Tributária como Instrumento de Efetivação de Direitos e o Reconhe- 
cimento da Prescrição Intercorrente nos Processos de Execução Fiscal no Município de Pelotas: Um estudo sobre os efeitos da aplicação da Súmula 314 do STJ e seus precedentes. TCC (Bacharelado em Direito) - Faculdade de Direito, Universidade Católica de Pelotas. Pelotas, p. 54, 2020.

7. BRASIL. Lei n. 5.172/66, de 25 de outubro de 1966. Dispõe sobre o Sistema Tributário Nacional e institui normas gerais de direito tributário aplicáveis à União, Estados e Municípios. Brasília, DF: Presidência da República, 1966.

8. BRASIL. Lei n. 5.172/66, de 25 de outubro de 1966. Dispõe sobre o Sistema Tributário Nacional e institui normas gerais de direito tributário aplicáveis à União, Estados e Municípios. Brasília, DF: Presidência da República, 1966.

9. "Art. 988. Caberá reclamação da parte interessada ou do Ministério Público para:

\section{$[\ldots]$}

IV - garantir a observância de acórdão proferido em julgamento de incidente de resolução de demandas repetitivas ou de incidente de assunção de competência;

\section{$[\ldots] "$.}

(BRASIL. Lei n. 13.105/15, de 16 de março de 2015. Código de Processo Civil. Brasília, DF: Presidência da República, 2015. Disponível em: http://www.planalto.gov.br/ccivil_03/_ato2015-2018/2015/lei/l13105. htm. Acesso em: 6 nov. 2020).

10. "Art. 927. Os juízes e os tribunais observarão:

$\S 3^{\circ} \mathrm{Na}$ hipótese de alteração de jurisprudência dominante do Supremo Tribunal Federal e dos tribunais superiores ou daquela oriunda de julgamento de casos repetitivos, pode haver modulação dos efeitos da alteração no interesse social e no da segurança jurídica". (BRASIL. Lei n. 13.105/15, de 16 de março de 2015. Código de Processo Civil. Brasília, DF: Presidência da República, 2015. Disponível em: http://www. planalto.gov.br/ccivil_03/_ato2015-2018/2015/lei//13105.htm._Acesso em: 6 nov. 2020).

\section{REFERÊNCIAS}

AMARO, Luciano. Direito Tributário Brasileiro. 2. ed. São Paulo: Saraiva, 1998.

BRASIL. Lei n. 5.172/66, de 25 de outubro de 1966. Dispõe sobre o Sistema Tributário Nacional e institui normas gerais de direito tributário aplicáveis à União, Estados e Municípios. Brasília, DF: Presidência da República, 1966. Disponível em: http://www.planalto.gov.br/ccivil_03/leis/l5172compilado.htm. Acesso em: 6 nov. 2020

BRASIL. Lei n. 6.830/80, de 22 de setembro de 1980. Dispõe sobre a cobrança judicial da Dívida Ativa da Fazenda Pública, e dá outras providências. Brasília, DF: Presidência da República, 1980. Disponível em: http://www.planalto.gov.br/ccivil_03/leis//6830.htm._Acesso em: nov. 2020

BRASIL. Lei n. 13.105/15, de 16 de março de 2015. Código de Processo Civil. Brasília, DF: Presidência da República, 2015. Disponível em: http://www.planalto.gov.br/ccivil_03/_ato2015-2018/2015/lei/113105. htm. Acesso em: 6 nov. 2020

BRASIL. Superior Tribunal de Justiça. Recurso Especial REsp. 1.340.553/RS/Distrito Federal. Relator: Min. Mauro Campbell Marques, 12 de setembro de 2018. Brasília: STJ, 2018. Disponível em: https:// stj.jusbrasil.com.br/jurisprudencia/638023415/recurso-especial-resp-1340553-rs-2012-0169193-3/inteiroteor-638023436. Acesso em: nov.2020. 
BRASIL. Superior Tribunal de Justiça. Recurso Especial 1641011/ Distrito Federal. Relator: Min. Napoleão Nunes Maia Filho, 14 de novembro de 2018. Brasília: STJ, 2018. Disponível em: https://stj. jusbrasil.com.br/jurisprudencia/651890180/recurso-especial-resp-1641011-pa-2016-0313842-4/inteiroteor-651890182. Acesso em: 6 nov.2020.

DINIFI, Luiz Felipe Silveira. Manual de Direito Tributário. 3. ed. São Paulo: Saraiva, 2006.

MACHADO, Hugo de Brito. Curso de Direito Tributário. 14. ed. São Paulo: Malheiros, 1998.

MENGADO, Bárbara. Recurso Repetitivo: STJ julga "modulação" de recursos repetitivos. Jota, São Paulo, 9 jun. 2016. Disponível em: https://www.jota.info/justica/stj-julga-modulacao-de-recursosrepetitivos-09062016. Acesso em: nov.2020.

PACHALSKI, L. Arrecadação Tributária como Instrumento de Efetivação de Direitos e o Reconhecimento da Prescrição Intercorrente nos Processos de Execução Fiscal no Município de Pelotas: Um estudo sobre os efeitos da aplicação da Súmula 314 do STJ e seus precedentes. TCC (Bacharelado em Direito) - Faculdade de Direito, Universidade Católica de Pelotas. Pelotas, p. 54, 2020.

RIO GRANDE DO SUL. Tribunal de Justiça. (Primeira Câmara Cível). Apelação Cível n 70080066525. Relator: Irineu Mariani, 19 dez. 2018. Porto Alegre: Tribunal de Justiça do Rio Grande do Sul, 2018. Disponível em: https://www.tjrs.jus.br/novo/busca/?return=proc\&client=wp_index. Acesso em: 6 nov. 2020.

RIO GRANDE DO SUL. Tribunal de Justiça. (Vigésima Segunda Câmara Cível). Agravo de Instrumento n. 70084384965. Relator: Luiz Felipe Silveira Difini: 29 jul. 2020. Porto Alegre: Tribunal de Justiça do Rio Grande do Sul, 2020. Disponível em: https://www.tjrs.jus.br/novo/busca/?return=proc\&client=wp_index. Acesso em: 6 nov. 2020.

RIO GRANDE DO SUL. Tribunal de Justiça. (1 ${ }^{a}$ Câmara Cível). Apelação Cível n 70081834947. Porto Alegre: Tribunal de Justiça do Rio Grande do Sul, 2019. Disponível em: https://www.tjrs.jus.br/novo/ busca/?return=proc\&client=wp_index. Acesso em: 6 nov. 2020.

Recebido em: 09/11/2020

Aceito em: 01/01/2021 